Saria 


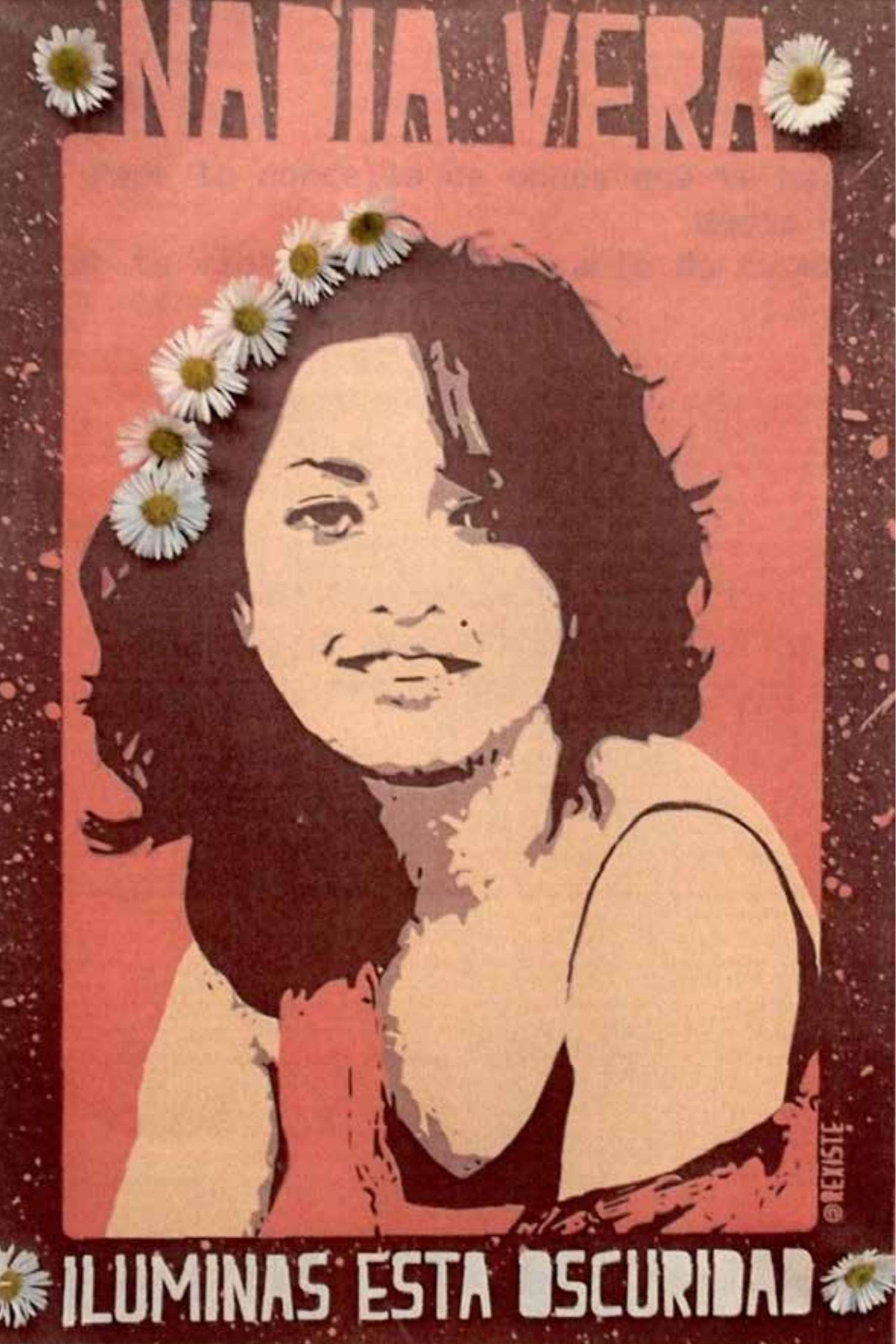




\title{
De Rodríguez a rodríguez freire. Cita, experimentación y forma crítica en el ensayo literario latinoamericano
}

\section{From Rodríguez to rodríguez freire. Citation, Experimentation and Critical Form in Literary Latin American Essay}

\author{
Efrén Giraldo \\ Universidad Escuela de Administración, \\ Finanzas y Tecnologías (EAFIT), Colombia \\ egiral25@eafit.edu.co
}

Una mirada a la historia del ensayo en América Latina revela que la búsqueda estética ha sido tan intensa como el objetivo crítico de sus planteamientos. Por un lado, el ensayo se acercó, en un movimiento de exploración de límites genéricos, a la novela, al diario y a la crítica, tras una línea que tuvo primero en Borges y después en Piglia a sus agentes. Por otro lado, el ensayo buscó aproximaciones a lo lírico, con el fin de formar un ámbito en el que pensamiento y metáfora habitan un espacio común. Alfonso Reyes, Octavio Paz, y después autores como Antonio José Ponte, representan bien esta manera "rapsódica", a la que Schlegel caracterizó como "poema intelectual".

Una tercera línea de estetización de lo ensayístico, y por ende de exploración artística de la escritura argumentativa, procede del acercamiento a otras escrituras no ficcionales, de las que el ensayo extrae principios de trabajo "enfático” sobre la forma de exposición, como diría Adorno en su texto de 1950. En esta línea, diario de lectura, nota, glosa y aforismo definen una apuesta siempre fragmentaria, minimalista, punzante, como en González Prada, Julio Torri o Nicolás Gómez Dávila.

Un tercer grupo de estrategias estéticas lleva el ensayo a la apertura de medios y soportes. Se trata de textos que dan un salto a otros lenguajes, bien por la incorporación de valores visuales y plásticos en su construcción, bien por 
su extensión al espacio que se forma entre medios. En lo que tiene que ver específicamente con el binomio palabra/imagen, se puede pensar en Alejo Carpentier y su libro con el fotógrafo Paolo Gasparini, o incluso en el precursor del ensayo como género visual: el venezolano Simón Rodríguez. En su obra el ensayo es artefacto verbal, pero también construcción plástica.

Rodríguez representa la cara experimental del ensayo porque somete el medio primario de la literatura — la palabra - y su inscripción —el armado de la caja tipográfica - a un replanteamiento. La exposición sigue la cadena hablada de las artes ilocutivas, temporales, pero también se vale de las posibilidades espaciales de la página para articular el sentido, como ocurre en las artes plásticas o visuales. - Aún no se ha explorado suficientemente el lugar que el experimento de Simón Rodríguez tiene en la discusión de la teoría estética de la separación de los medios artísticos de Lessing-.

A todas estas, y más allá de las inquietudes por los límites entre medio verbal y medio visual, sobreviene una pregunta: ¿ existe una tradición experimental en el género ensayístico?

Ante la posibilidad de una conclusión afirmativa, surge el esbozo de dos respuestas. La primera es que la dimensión experimental, el tanteo y la exploración son esenciales al ensayo, dado que su territorio es el de una indagación de contenido y de forma. En tal sentido, el ensayo se convierte en depositario del modernismo estético, pues la búsqueda de formas y recursos alternativos culmina en autocrítica. Al no ser una forma estructuralmente fijada, las posibilidades de innovación y autorreferencia se mantienen siempre abiertas. No hay en el ensayo una estructura contra la que el ensayista contemporáneo pueda rebelarse, como hicieron Joyce y Proust con la linealidad narrativa y el punto de vista omnisciente o Whitman con la rima y el metro. De hecho, el ensayo sería una forma que, con Montaigne, surgió abierta y, como dice Huxley, "adulta".

La segunda respuesta es un poco más compleja, pues admite que, aun en esa tradición abierta, hay una forma ensayística clásica, fijada a lo largo de los últimos siglos, en la que predomina el discurso argumentativo y que sostiene una autonomía constructiva. Mientras con Montaigne estamos ante el ensayo de familia autocrítica, con Bacon tendríamos el ensayo como género, como una estructura, no poetológica sino retórica. De acuerdo con esa perspectiva, el ensayo como género exploraría nuevas estrategias formales en el siglo xx, cruzaría los linderos discursivos, las márgenes de los modos de enunciación que le son familiares y se aventuraría en caminos innovadores. 
Sea cual sea la opción - la de un experimentalismo ensayístico de raíz o la de un tipo de ensayo que se rebela contra las formas convencionales de la literatura - resulta obvio que existen muchos ejemplos de ensayo experimental en América Latina y que allí se encuentra el principal lugar de residencia del ensayo como forma autocrítica, según expuso Miguel Gomes. La historia del ensayo latinoamericano podría escribirse exclusivamente bajo ese principio, y el recuento ofrece no pocas sorpresas. Esa historia comienza, probablemente, con el propio Simón Rodríguez y termina con Antonio José Ponte, pasa por Sarmiento, Martí, Reyes, Torri, Cortázar, Paz, Gómez Dávila y tiene un punto de plenitud en las ficciones críticas de Borges y Piglia.

El libro de raúl rodríguez freire, siempre con minúsculas, se afilia con una tradición en la que la dimensión crítica, el peso de los datos y la exasperación ética acompañan una cuidadosa y novedosa factura. La condición intelectual. Informe para una academia comparte con la tradición ensayística "clásica" todas las actitudes propias del ethos del ensayista y las vuelve asunto de reflexión. Más aun, convierte el género, el discurso que lo caracteriza principalmente - la argumentación-, en recurso puesto al servicio de la asunción crítica del soporte. Abundan múltiples juegos con la apropiación de voces, con la manera de citar y de configurar con medios mixtos — de imagen y palabra- el milagro de la página, ese milagro en el que la tradición de Simón Rodríguez hace confluir la ideación, la producción y la preparación en un trabajo de artesanía.

Y es precisamente en su crítica al trabajo abstracto y en su recurrencia a los privilegios de la materialidad donde se halla uno de los puntos nodales. La idea de materialidad logra convertirse, en el libro de rodríguez freire, no solo en un juego formal decorativo, sino más bien en una apelación profunda: la necesidad de que el trabajo intelectual en la era del capitalismo tardío, proletarizado por las universidades, los medios masivos y las redes sociales, vuelva a reconocer su dimensión fabril. El libro, de hecho, parece un acto de composición tan objetual como intelectual, tan crítico como recreativo. El libro acaba en invitación a que otros ensayistas ensayen gestos editoriales semejantes. Como recuerda la estética analítica, la forma es sentido encarnado.

Y es que, en cierta medida, el antecedente más evidente de La condición intelectual es el ejercicio tipográfico experimental desarrollado por el cajista Simón Rodríguez en Sociedades americanas. Simón Rodríguez es, como 
Bello, como García del Río, un ensayista-trabajador, un tipo de autor que mostró el lugar especial que el ensayo puede tener como forma crítica y estética, por vía de su vinculación con la materialidad de la escritura. De esta manera, en ambos casos, en el de finales del siglo XVIII y en el de principios del XxI, la configuración formal del ensayo se torna alegórica. Lo que en Rodríguez fue trabajo con el espacio tipográfico bidimensional, en rodríguez freire es apelación a las posibilidades de la cita y el soporte de inscripción de las ideas.

Este interés en la forma enunciativa y en la crítica a las costumbres fosilizadas de la producción académica, que le permite hacer múltiples juegos, interesantemente reproducidos en el diseño editorial, nos lleva a otra voz tutelar: la de Walter Benjamin en "El autor como productor". A este texto, rodríguez freire lo sigue no solo temáticamente, sino en sus apelaciones más importantes. Se advierte en la peculiar manera de citar del ensayista chileno una estrategia de afiliación benjaminiana: La condición intelectual es una crítica al modo habitual de citar de la tecnocracia, pero también una suerte de declaración sobre la potencia estética de este recurso, uno de los más importantes del ensayo literario. Lo mismo podría decirse de la bibliografía del libro, sección en la que rodríguez freire hace un verdadero juego de manos, un performance escritural llamativo.

Ahora bien, como informe de lectura del texto de Benjamin, el libro de rodríguez freire recoge y aplica algunos de los planteamientos que involucran las estrategias del montaje y el collage, algo que resulta más o menos fácil de extrapolar a los terrenos de la lírica y la narración, pero menos habitual cuando hablamos de las artes del ensayo. Como señaló Peter Bürger, quien en ello sigue también a Benjamin, ambas operaciones, collage y montaje, resultan emblemáticas de la nueva concepción de la forma en la vanguardia. El llamado Libro de los pasajes y Calle de dirección única asoman tras las páginas del libro de rodríguez con su apelación a las voces ajenas como bloques de tiempo, pero también de espacio, objetos extractados del marco editorial ajeno para ser incorporados en el propio texto.

Pero, por otro lado, el ensayista chileno parece hacer una lectura, todavía en clave benjaminiana, del mundo académico contemporáneo: el de los índices, el arbitraje, las acreditaciones, los rankings, la citabilidad y la visibilidad. Allí está su principal objeto de crítica. Para ello, La condición intelectual sigue al escritor alemán en las más profundas sugestiones de su conocido ensayo "El autor como productor". Sorprende, por supuesto, que también sobre estas 
materias, que se creerían exclusivas de nuestro tiempo, el ensayo de Benjamin tenga algo que decir.

El trabajo cultural, la escritura, el oficio de pensar y la enseñanza reciben los rigores analíticos ostentados en el texto visionario de Benjamin con la cultura letrada de su época. La síntesis, con la visión aportada por rodríguez freire, es por lo menos inquietante. Al Benjamin que no dudaba en que todo escritor debía primero interrogar críticamente el aparato que lo sustenta y el orden social en el que se encuentra inscrito, le sigue un rodríguez freire profundamente escéptico, hilarantemente escéptico, con el destino de las actividades intelectuales y universitarias de nuestro tiempo. Aquí el tema, como en todo buen ensayo, se muestra filoso: el ensayista siente que debe advertir peligros y señalar perniciosos desenlaces para una situación cultural. En manos del articulismo académico, la bibliometría y los algoritmos que rigen la manera en que recibimos y hacemos circular la información, la actividad intelectual ha derivado en ejercicio dócil e inane, en una suerte de galería de exhibición del yo en la que quienes se mediatizan colaboran con su propia explotación.

El mundo de la academia 2.0 abandona su espacio cómico y pasa a ser un hecho sociológico. Por eso, el análisis, penetrante y documentado de La condición intelectual, como en todo buen ensayo, discute estos asuntos como un fenómeno de profundas implicaciones, en este caso para la vida universitaria, la crítica y la actividad intelectual. El análisis de Academia.edu, ISI y scOPUs, Facebook y Twitter como lo que son finalmente, esto es, como lucrativas empresas que se sostienen por los contenidos que generan los propios intelectuales, tiene un lugar destacado.

$Y$ es en este punto, en su análisis del trabajo intelectual, y en su lectura marxista del trabajo contemporáneo y su grave crisis, como el libro logra dar en el clavo. Supera de esta manera la propensión a la sátira que leemos en las ironías y lamentos que habitualmente se escriben contra las publicaciones indexadas y la sociedad del mutuo elogio en que se convierten los espacios académicos e investigativos. El libro se torna, por vía de su propia advertencia, en un texto indispensable bajo la persona de una nueva forma ensayística, en actitud crítica y editorial. Me temo que en algún momento, cuando las múltiples crisis que acechan a la tecnocracia académica se hagan presentes, volveremos a este libro de raúl rodríguez freire. Ahí reside, tal vez, la importancia de su gesto humanista (pero no metafísico), en la genuina preocupación que instala. Pero también, y sobre todo, en retornar 
al instrumento ensayístico, esta vez bajo su cara más experimental, en el verdadero revulsivo contra el actual mundo de las actividades intelectuales y académicas.

¿Por qué? Porque quizás el ensayo tiene desde su mismo origen ese gesto contra las convenciones y las malas costumbres de los letrados que ahora recupera este libro. Y también porque, en su terquedad frente a la forma, es siempre un género potencial, anterior a toda fosilización — La buena fe, tal como la define Montaigne desde sus palabras al lector, sería un correlato para someter a juicio buena parte de las publicaciones académicas de hoy y de los móviles que rigen la vida pública de los intelectuales-. Lo que resulta renovador en este libro es que el autor añada a la crítica humanista de la academia contemporánea —ya está más o menos establecida - una particular lectura inspirada en los primeros experimentos mediales del ensayo en América Latina - rodríguez-y en una lectura estratégica que cruza al Benjamin autor y artista con el Benjamin crítico de la misma autoría.

¿Qué queda por hacer? A mi juicio, además del gesto de resistencia editorial y societal propuesto por el libro, un par de cosas. Una, afirmar la autonomía del ensayo y de la familia de géneros ensayísticos no académicos como una manera de resistir al articulismo académico dominante, algo en lo que el libro vacila un poco, acaso porque no reconoce en el ensayo una instancia contemporáneamente definitiva. En segundo término, dar paso a lo que proponen Hal Foster y Claire Bishop en sus análisis de los paradigmas artísticos de la segunda mitad del siglo xx.

Recordemos: la lectura de Benjamin deriva, por vía de su convocatoria a politizar el arte, en estrategias fundamentalmente productivistas - el libro de rodríguez freire es, por forma, por vocación y por propuesta, "productivista”, en la misma línea de Tetriakov y Heartfield-. Tales estrategias deberían conducir a otras dos, más acordes con nuestra actual condición. Una, de carácter situacionista, abriría al intelectual a una dimensión política más comprometida con la creación de situaciones, Zonas Temporalmente Autónomas (Bey) para fomentar una mejor lectura y escritura críticas. Otra, de orden participativo, buscaría estrategias de convergencia, para ir en busca de más y mejores formas de representación política en el debate.

Y es que, a pesar de que el libro se centra sobre todo en el autor, en el intelectual y el profesor, es obvio que rodríguez freire confía sobre todo en los lectores. En ellos es donde prenden las situaciones e instancias de participación que La condición intelectual anticipa. Mientras las artes visuales tienen 
a un espectador al que le cuesta alejarse de la inercia del espectáculo, las artes literarias tienen al lector que, aun en medio de los riesgos del solipsismo, agencia formas impensadas de emancipación. No resulta extraño por lo tanto que, frente a las liquidaciones del emprendimiento cultural y el capital humano, que por vía de la cultura digital han dado alcances impensados a la degradación del trabajo, sea el libro impreso el que condense estas aspiraciones. Imprimir sobre papel un ensayo experimental es, impensadamente, uno de los pocos gestos que nos quedan.

\section{Efrén Giraldo}

Doctor en Literatura por la Universidad de Antioquía. Ensayista, crítico, investigador y profesor universitario en la Universidad EAFIT. Pertenece al grupo de investigación en Estudios en Filosofía, Hermenéutica y Narrativas de la misma institución. Obtuvo el Premio Nacional de Literatura Universidad de Antioquia en 2012 y el Premio Nacional de Curaduría Histórica del Instituto Distrital de las Artes y la Fundación Gilberto Alzate Avendaño de Bogotá en 2013. Desde 2015 coordina el Taller de Crítica de Medellín, un espacio independiente de apoyo a la escritura crítica y el debate sobre las artes y la cultura. Entre sus libros están Los límites del índice (2010), Entre delirio y geometría (2013) y La poética del esbozo (2014). Sus intereses de investigación se enfocan en el ensayo literario, la historia de las ideas, la narrativa moderna y contemporánea, las relaciones interartísticas, la estética y el arte contemporáneo. 